\title{
Total Fertility Rate, Women's Education, and Women's Work: What Are the Relationships?
}

\author{
Kristi McClamroch \\ University of Michigan
}

\begin{abstract}
This paper presents the results of a statistical study, using cross-national data, on the relationships between total fertility rate and women's level of education and women's labor participation. Aggregate data on seventy-one countries were collected from numerous sources. Eight variables related to women's fertility, mortality, economic status, labor participation, and education are analyzed using multivariate linear regression analyses. Two models are considered. The first model regresses five variables on total fertility rate: per capita Gross National Product (GNP), percentage of women ages 15 to 19 who are married, female life expectancy at birth, calories available as a percentage of need, and percentage of married couples using contraception. The second model includes two additional regressors: the average number of years of schooling for women, and the percentage of women in the labor force. These seven variables are regressed on total fertility rate. Although the data are crude, the results of the analyses suggest that the model which incorporates women's level of education and women's labor participation captures the data better than the smaller model. The full model suggests that the percentage of women in the labor force is directly related to total fertility rate, whereas the average number of years of education for women is indirectly related to total fertility rate.
\end{abstract}

\section{INTRODUCTION}

Human population growth is a serious concern. Worldwide human population is growing rapidly and, if unchecked, could lead to frightening

Please address correspondence to Kristi McClamroch, Population-Environment Dynamics Project, University of Michigan, SPHII, Ann Arbor, MI 48109-2029.

Population and Environment: A Journal of Interdisciplinary Studies Volume 18, Number 2, November 1996 
consequences (Ehrlich \& Ehrlich, 1990, p. 17). Fertility levels in many countries are significantly above replacement level, while in many low fertility countries, consumption is very high. Uncontrolled population growth could result in worldwide lowered standards of living and further depletion of natural resources. It is vital that the factors which relate to total fertility rate be understood.

For the last 30 years, many demographers have expected that industrialization would decrease fertility rates, based on their assumption that nineteenth century Western European and North American family sizes fell with industrialization. The data are complex, and current observations indicate that fertility is not declining with industrialization in the developing world. A more complete explanation of fertility is needed.

One current hypothesis is that an increase in women's level of education and women's labor participation will decrease fertility. According to Ruth Dixon-Mueller (Dixon-Mueller, 1993), education for women can indirectly decrease fertility in three ways. Increasing the number of years that women are in school delays marriage and reduces the time duration that women are exposed to the possibility of conception. Education creates aspirations for higher standard of living, thereby decreasing the desired number of children in a family. Education exposes women to "knowledge, attitudes, and practices favorable to birth control" that would enable women to have their desired number of children. Dixon-Mueller also suggests that increased labor participation gives women "alternative sources of social identity and economic support [thereby reducing] women's dependence on men and children" (Dixon-Mueller, 1993, pp. 121-123).

This paper discusses some statistical results using aggregate data from seventy-one countries. Eight variables related to women's fertility, mortality, education, labor participation, and economic status are analyzed using multivariate linear regression analyses. Some variables are clearly proximate correlates to fertility, while others have been postulated to have influence. Two models are considered. The first model regresses five variables on total fertility rate: per capita Gross National Product (GNP), percentage of women ages 15 to 19 who are married, female life expectancy at birth, calories available as a percentage of need, and percentage of married couples using contraception. The second model includes two additional regressors: the average number of years of schooling for women, and the percentage of women in the labor force. These seven variables are regressed on total fertility rate. The two models are studied. Because it is difficult to obtain data for many countries, only seventy-one selected countries for which complete data could be obtained are included in the analysis. 
KRISTI MCCLAMROCH

\section{DATA SOURCES}

Data on fertility, education, labor participation, and other socioeconomic variables have been collected for one hundred and eighty countries. Eight variables are identified as central. Since it is extremely difficult to find current data (data from 1980 to 1993) for many countries, particularly for poor and less developed countries, the final data set consists of seventy-one countries. Of the seventy-one countries, fourteen countries are in Africa; sixteen countries are in Asia; seventeen countries are in the Americas; twenty countries are in Europe; three countries are in Oceania; the former USSR is considered one country. The six most populous countries of the world are included: China, India, United States, Indonesia, Brazil, and the former USSR. Figure 1, which shows these seventy-one countries on a world map, illustrates that the data set is a geographically representative sample of the world's countries.

Data for the seventy-one countries have been collected from various sources. Total fertility rate, a hypothetical cohort measure, is the number of births per woman if all women experienced the age specific birth rates of a particular year at every reproductive age (Weeks, 1994, pp. 117-118). The data for total fertility rate have been collected from World Resources (1990, Table 16.2, pp. 256-257) for various total fertility rates measured between 1985 and 1990 . Total fertility rate is the response variable in both multiple regression models.

Data for the five dependent variables have been collected from various sources. Female life expectancy at birth, a hypothetical cohort measure, is the number of years that women would be expected to live on average, if they experienced age specific death rates of a particular year at every age of their life (Ehrlich \& Ehrlich, 1990, pp. 171). Data on female life expectancy at birth have been collected from Population Policy and Women's Rights: Transforming Reproductive Choice (Dixon-Mueller, 1993, Appendix B, pp. 232-238) for various female life expectancies at birth for 1990 . The second regression variable is the percentage of women between the ages of fifteen and nineteen years of age who are married, rather than the total percentage of women who are married, because it is hypothesized that women who marry early have more children (Dixon-Mueller, 1993, p. 16). These data for sixty-seven countries have been collected from Population Policy and Women's Rights: Transforming Reproductive Choice (Dixon-Mueller, 1993, Appendix B, pp. 232-238). These data for Algeria, El Salvador, Honduras and Colombia have been calculated from the 1991 Demographic Yearbook (1992, Table 24, pp. 497-506) by dividing the number of women ages fifteen to nineteen who are married by the total 


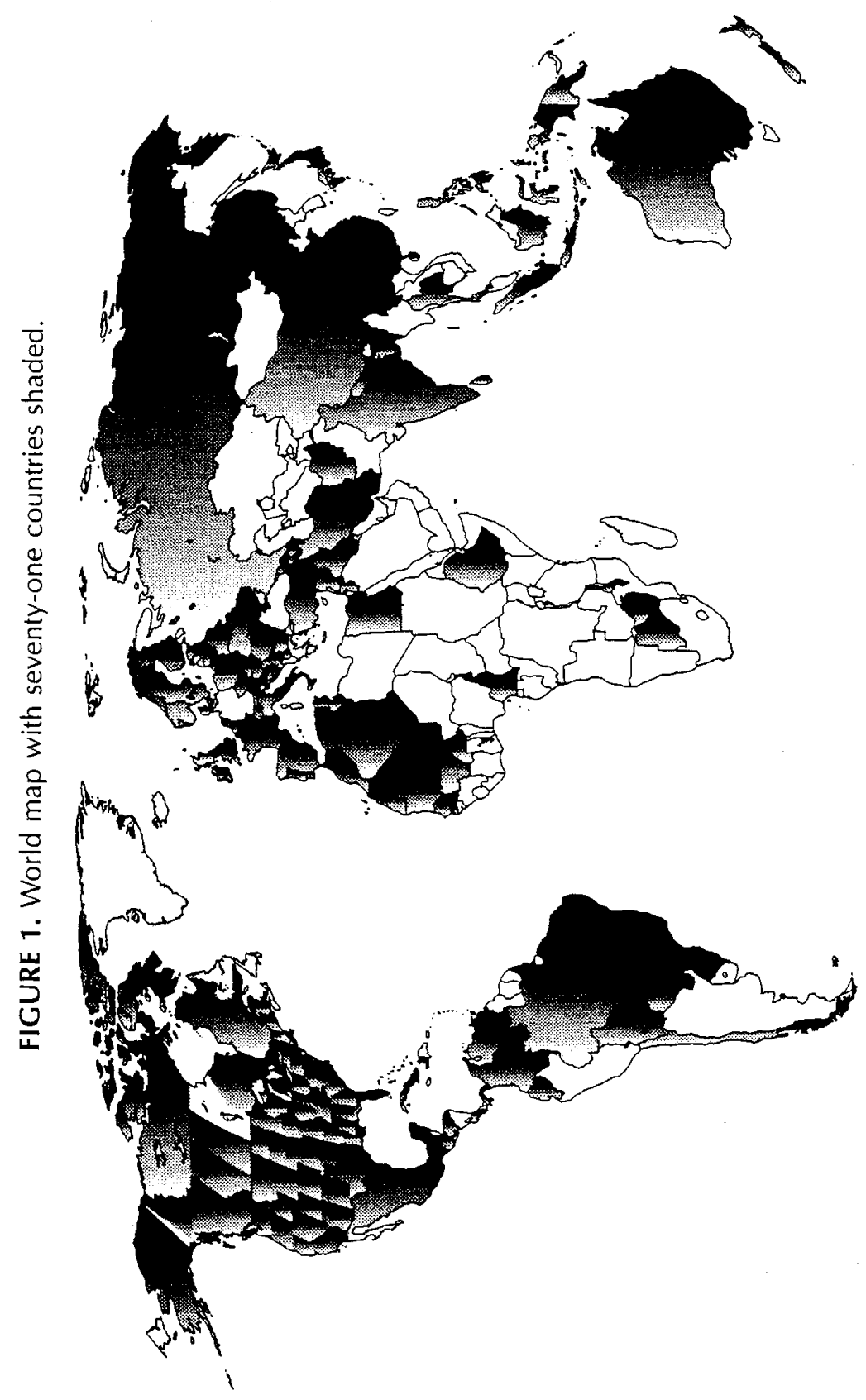


KRISTI MCCLAMROCH

number of women in the country. Data on per capita Gross National Product (per capita GNP) for sixty-four countries have been collected from Population Policy and Women's Rights: Transforming Reproductive Choice (Dixon-Mueller, 1993, Appendix B, pp. 232-238) for the year 1990. Per capita GNP for Iran, Romania and the former USSR have been collected from the "1993 World Population Data Sheet" (1993). Per capita GNP for Afghanistan and Iraq have been collected from the 1993 World Almanac and Book of Facts $(1992$, pp. 727, 764). Per capita GNP in 1980 for Cuba and Czechoslovakia have been collected from Women. A World Survey (Sivard, 1985, pp. 39-41). Data from 1983 to 1985 for the average number of calories available as a percentage of need for sixty-four of the countries have been gathered from World Resources (1990, Table 16.3, pp. 258259). These data for Ethiopia, Iraq, Jordan, Afghanistan, Iran, El Salvador and Paupau New Guinea for 1984/1986 have been collected from 1993 Statistical Yearbook (1993, Table 22, pp. 179-185). 1980 to 1987 data on the percentage of married couples using contraception have been collected for sixty-two countries from World Resources (1990, Table 16.5, pp. 262263). Data for the percentage of women using any form of contraception as a measure of the total for Algeria, Australia, Ethiopia, Iran, Ireland, and the former USSR have been collected from the "1993 World Population Data Sheet" (1993). These contraception data for Burkina Faso, Chile, and Paupau New Guinea have been collected from Women In The World: An International Atlas (Seager \& Olsen, 1986, Country Table, pp. 92-99).

The final two variables, which measure women's level of education and women's labor participation, are used as independent variables in the second multiple regression model only. Data on the number of women in the labor force in 1990 as a percentage of the total number of men and women in the labor force have been collected from The World's Women (1991, Table 8, pp. 104-107). Data on the average number of years of education for women have been collected from "Closing the Gender Gap: Educating Girls" (1993). Although it is easier to find data on the percentage of women in secondary school, the average number of years of education is considered in this research because it measures the length of time that women remain in any level of school (primary, secondary or post-secondary).

The data used in this research are crude for three reasons. First, many countries are not represented in these analyses. Second, it is difficult to measure accurately many of these variables in countries that are poor and underdeveloped. Third, although these data are "current" they refer to an interval of time that spans thirteen years. Because the data are crude, the limitations on the following statistical analyses should be recognized. 


\section{CONSTRUCTION OF REGRESSION MODELS}

The main purpose of this research is to determine how women's level of education and women's labor participation relate to variations in worldwide total fertility rates. Two multiple regression models are constructed using the collected data. The first model, denoted by $\omega$, regresses total fertility rate on per capita CNP, percentage of women ages 15 to 19 who are married, female life expectancy at birth, percentage of calories available, and percentage of married couples using contraception. The second model, denoted by $\Omega$, regresses total fertility rate on the regressors in model $\omega$, but also includes measures of women's level of education and women's labor participation. These variables are the average number of years of education for women, and the percentage of women in the labor force. Tables $1 \mathrm{~A}$ and $1 \mathrm{~B}$ summarize the regression results for models $\omega$ and $\Omega$.

\section{INTERPRETATION OF REGRESSION RESULTS}

Based on the adjusted squared multiple $R$ value, the model $\omega$ explains $83.2 \%$ of the variance in total fertility rate (Table $1 \mathrm{~A}$ ). The model $\Omega$, which includes the average number of years of education for women and the percentage of women in the labor force, explains $86.1 \%$ of the variance in total fertility rate (Table $1 \mathrm{~B}$ ). Comparing these two models, $F(2,63)=7.28$, $p=0.00143$. Therefore, the model $\Omega$ provides significantly improved explanatory power. Women's level of education and women's labor participation appear to have significant influence on total fertility rates. This confirms the utility of including a measure of both women's level of education and women's labor participation as indices of total fertility rate.

It is also of interest to separately consider the relationships between women's level of education and total fertility rate, and women's labor participation and total fertility rate. Figure 2 shows the relative values of the standardized coefficients of the seven regressors in $\Omega$. The values of the standardized coefficients decrease clockwise (in absolute value), starting with percentage of married couples using contraception. The $P$ value and the standardized coefficient for the average number of years of education for women suggest that, in the presence of the other variables in the model, its correlation with total fertility rate is insignificant $(\alpha=0.05)$. In fact, this variable has the lowest standardized coefficient. In contrast, the $P$ value and the standardized coefficient for the percentage of women in the labor force suggest that, in the presence of the other variables in the model, its 


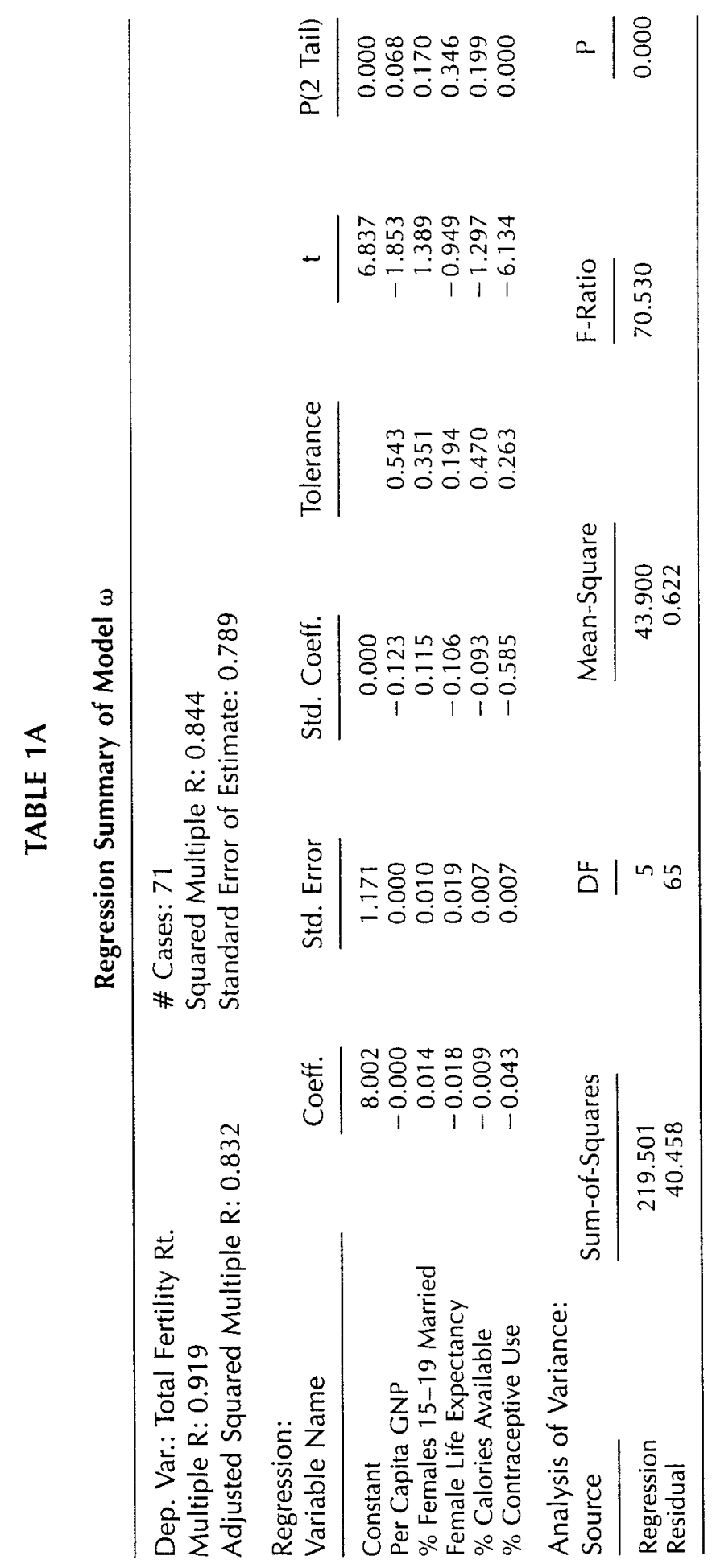




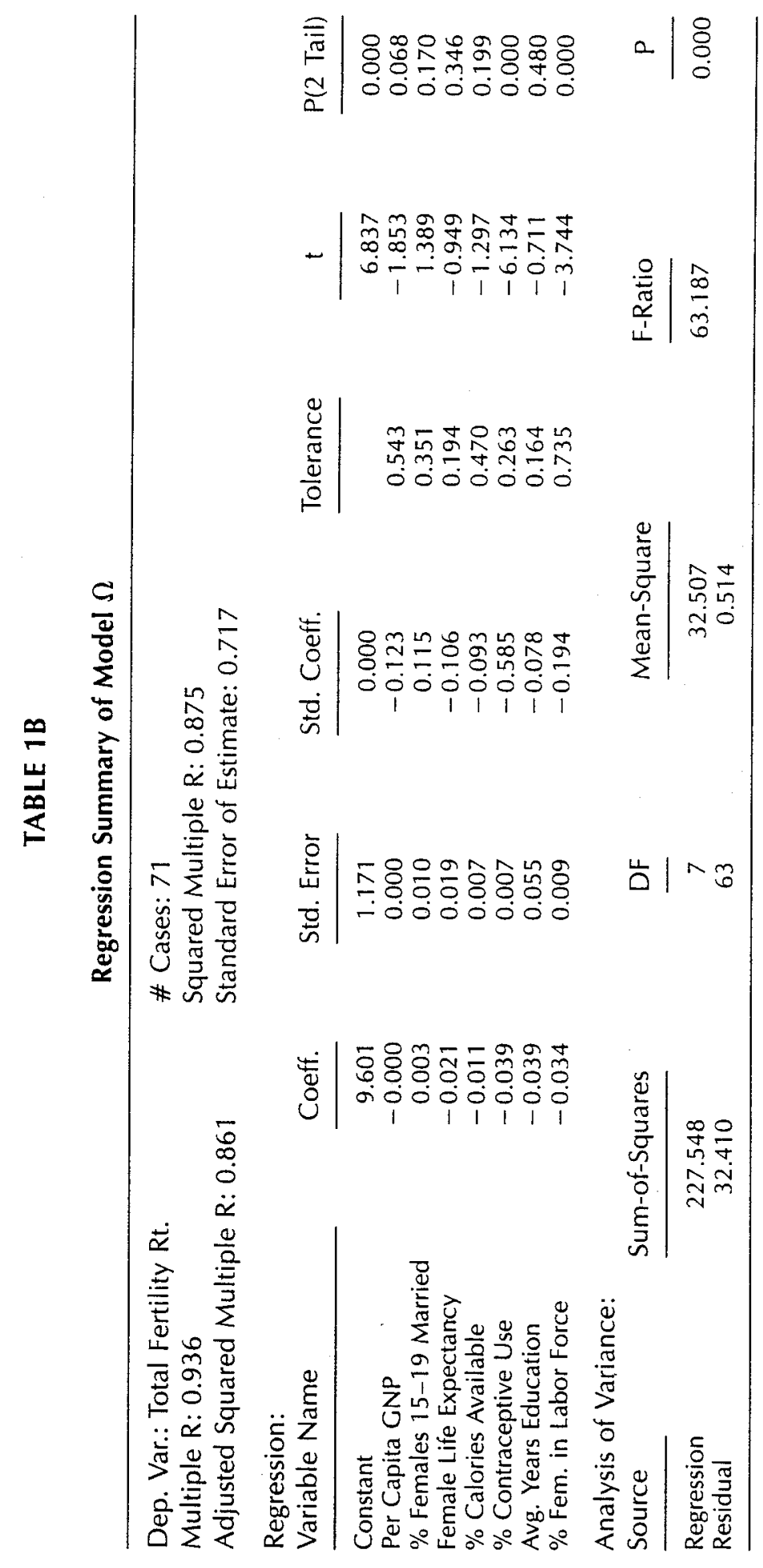


KRISTI MCCLAMROCH

FIGURE 2. Relative standard coefficients.

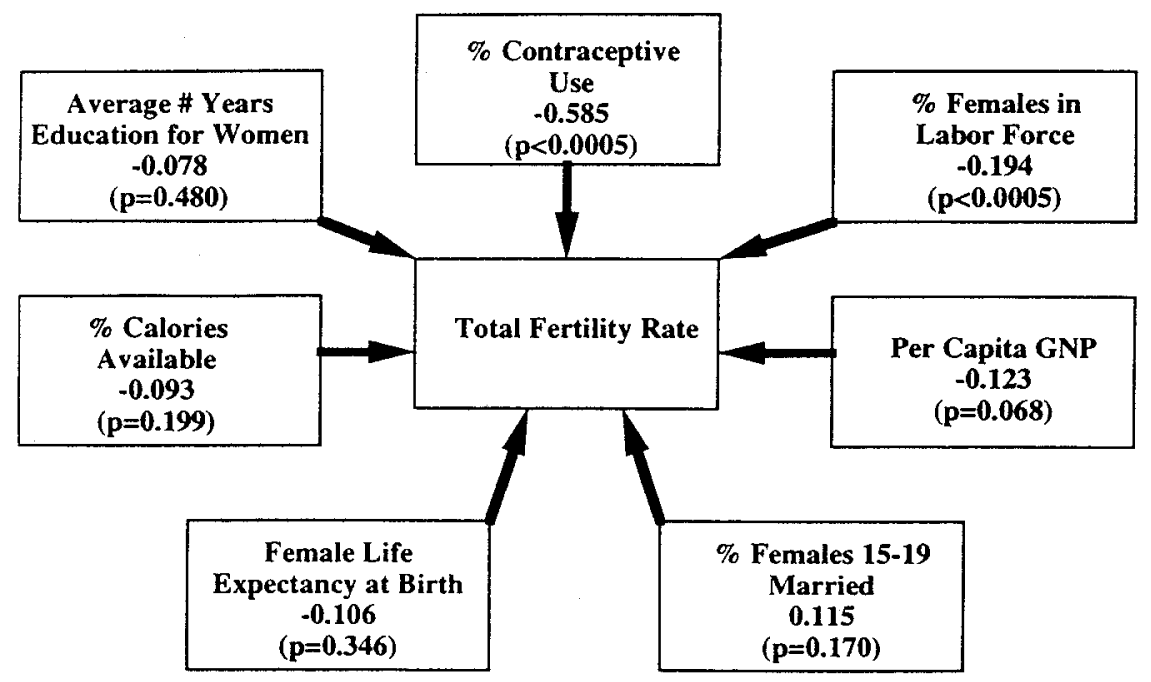

direct correlation with total fertility rate is significant $(\alpha=0.05)$. In fact, the percentage of women in the labor force has the second largest standardized coefficient, following only the percentage of couples using contraception. The data clearly show that the percentage of couples using contraception, in the presence of the other variables in the model, is the most important variable in explaining total fertility rate, providing explanation for $58.5 \%$ of its variance. The other four variables provide modest explanation of the variance in total fertility rate.

The seven regressors from $\Omega$ are multicollinear, creating complications in analysis. Figure 3 shows the relative correlations between these variables from the Pearson correlation matrix. Not only is the percentage of women in the labor force important in explaining total fertility rate, it has relatively low correlations with the other six regressors. All of the five socioeconomic factors are multicollinear (with correlations greater than 0.5, except for the correlation between the percentage of calories available and per capita GNP). The average number of years of education for women is the least significant variable, and is highly correlated with all other variables, except the percentage of women in the labor force. These correlation results imply that although the average number of years of education for women is not directly related to total fertility rate, it is highly correlated with other variables, particularly the percentage of married couples using contraception, that are directly related to total fertility rate. 


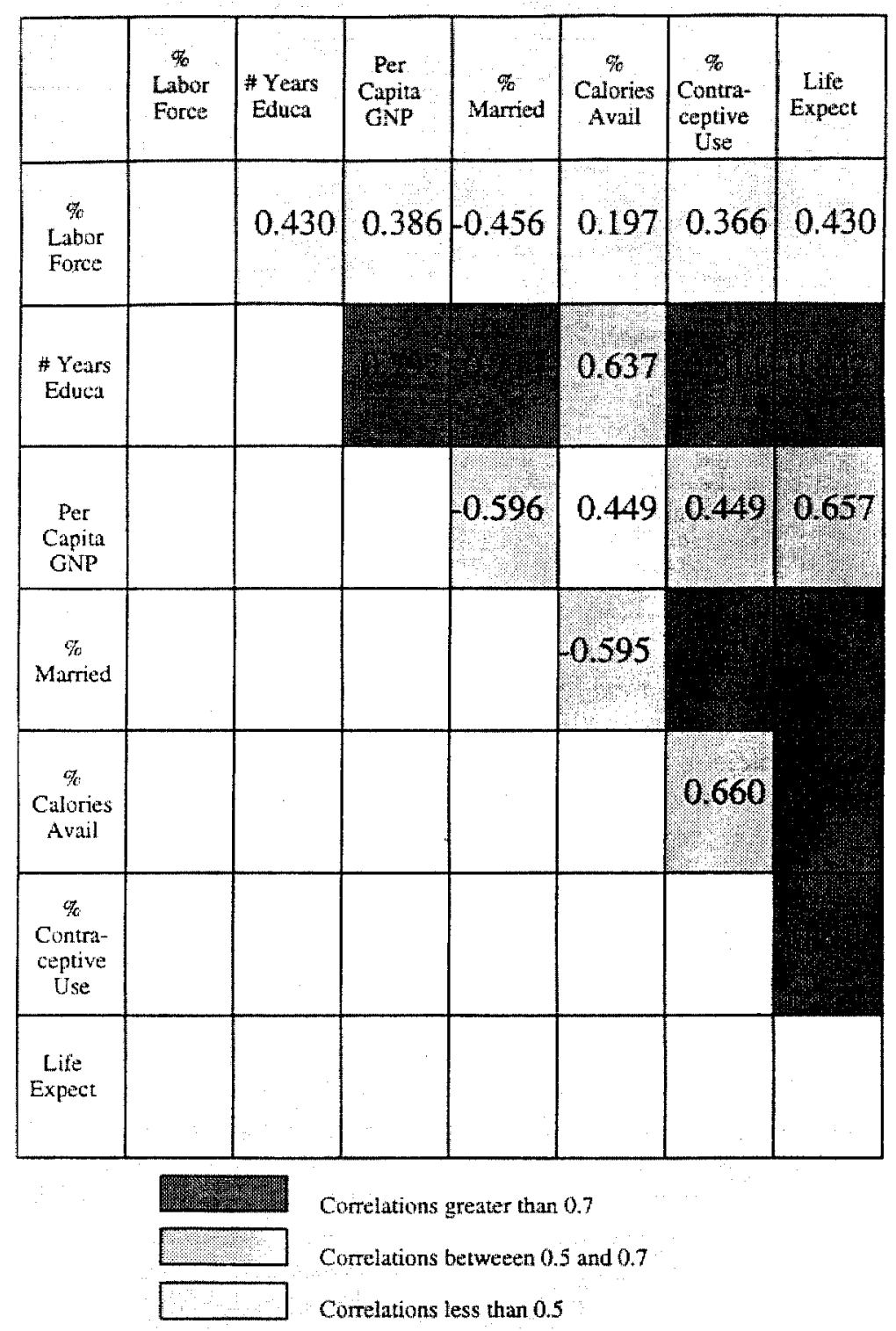


KRISTI MCCLAMROCH

\section{CONCLUSIONS}

This research supports the hypothesis that women's level of education and women's labor participation, together with other commonly considered socioeconomic variables, including percentage of married couples using contraception, are important in quantifying the variation in total fertility rate. A model which includes per capita Gross National Product, percentage of women ages 15 to 19 who are married, female life expectancy at birth, calories available as a percentage of need, and percentage of married couples using contraception, does not capture the data on total fertility rate as well as a model which includes these variables and average number of years of education for women and the percentage of women in the labor force. In the comprehensive model, women's labor participation and the percentage of married couples using contraception, separately, are directly correlated with total fertility rates. Education, which is not directly related to total fertility rate, is highly correlated with the percentage of married couples using contraception. Therefore, it has an important indirect relationship with total fertility rate.

This research has important implications for population growth policy. It has been shown that the percentage of married couples using contraception and the percentage of women in the labor force are the most critical variables related to total fertility rate, according to the models studies. Percentage of married couples using contraception is highly correlated with other independent variables in the model, whereas percentage of women in the labor force is relatively uncorrelated with the other independent variables. This suggests that policies that focus on contraceptive use relate to total fertility rate in a relatively complicated way due to the multivariate nature of its part in the regression model. On the other hand, policies that focus on women's labor participation have a more direct and quantifiable relationship with total fertility rate. This research indicates that the role of women's level of education is more ambiguous than the role of labor participation.

Because the data used in this study are crude, further analysis of the relationships between these variables is needed. Complete current crossnational data are difficult to obtain on many socioeconomic variables, especially for less developed countries. More complete data are essential in further research of this kind. Future research could refine the comprehensive model used in this study. Further analyses, using more complete data, could provide a better basis for understanding fertility trends and forming population policy decisions. 


\section{ACKNOWLEDGMENTS}

The author is grateful to Carl Simon and Bobbi Low, who supported this work through an NSF 'Research Experience for Undergraduates' Project, and to Laura Klem and Kathy Welch for their statistical guidance.

\section{REFERENCES}

Dixon-Mueller, R. (1993). Population policy \& women's rights: Transforming reproductive choice. Westport, Connecticut: Praeger.

Ehrlich, P.R., \& Ehrlich, A.H. (1990). The population explosion. New York: Simon and Schuster.

Population Reference Bureau (1993). 1993 world population data sheet. Washington D.C: Population Reference Bureau, Inc.

Population Action International (1993). Closing the gender gap: Educating girls. Population Action International.

Seager, J., \& Olsen, A. (1986). Women in the world: An international atlas. New York: Simon and Schuster.

Sivard, R.L. (1985). Women . . a world survey. Washington D.C: World Priorities.

United Nations (1992). 1991 demographic yearbook (43rd ed.). New York: United Nations.

United Nations (1993). 1993 statistical yearbook (38th ed.). New York: United Nations.

Weeks, J.R. (1994). Population: An introduction to concepts and issues. Belmont, California: Wadsworth, Inc.

World Almanac and Book of Facts 1993. (1992). New York: Newspaper Enterprise Association.

World Resources Institute in collaboration with The United Nations Environment Programme. (1990). World resources 1990-91. New York: Oxford University Press.

The World's Women: Trends and Statistics 1970-1990. (1991). New York: United Nations. 